\title{
Journal of Advanced Nutrition and Human Metabolism
}

Copyright (c) 2015 Lívia de Lacerda de Oliveira Pineli, Renata Puppin Zandonadi, Raquel Braz Assunção Botelho, Viviani Ruffo de Oliveira, Lúcio Flávio de Alencar Figueiredo

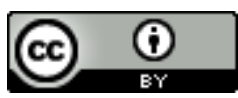

This work is licensed under a Creative Commons Attribution 4.0 International License.

Fonte: http://www.smartscitech.com/index.php/JANHM/article/view/944 


\title{
The use of sorghum to produce gluten-free breads: A systematic review
}

\author{
Lívia de L. de O. Pineli ${ }^{1}$, Renata P. Zandonadi ${ }^{1}$, Raquel B. A. Botelho ${ }^{1}$, Viviani R. de Oliveira ${ }^{2}$, Lúcio F. de Alencar \\ Figueiredo $^{3}$ \\ ${ }^{1}$ Department of Nutrition, College of Health Sciences, Campus Universitário Darcy Ribeiro, Universidade de Brasília, Brasília, DF, \\ 70910900, Brazil \\ ${ }^{2}$ Department of Nutrition, College of Medicine, Federal University of Rio Grande do Sul, Porto Alegre, RS, 90035003, Brazil \\ ${ }^{3}$ Department of Botany. Institute of Biology, Campus Universitário Darcy Ribeiro, Universidade de Brasília, Brasília, DF, 70910900, \\ Brazil
}

Correspondence: Lívia Pineli

E-mail: liviapineli@unb.br

Received: August 03, 2015

Published online: August 19, 2015

Sorghum is a strategic gluten-free crop cereal for food security due to its tolerance to drought and heat environment, with an interesting composition related to its similarity to corn, aggregated to resistant starch and phenolic compounds in many of the accessions. Sorghum grains should be applied for human consumption in several gluten-free products, such as breads. We assessed application of sorghum to make gluten-free breads (GFB) and to evaluate the advantages already achieved in its use, and what challenges remain. We searched electronic databases and bibliographies published from January 2005 to June 2015 by using the keywords sorghum, bread and gluten-free, and eleven studies on sorghum GFB were included. Sorghum GFB were developed mainly with red and white commercial sorghum flours and little information was provided about accessions. Only one of the studies has explored nutritional advantages of sorghum flour on glycemic index of bread. The other studies have focused on technological approaches to improve bread quality, which involved germination of sorghum grains, high pressure, application of sourdough and the use of starches and additives. Positive results were achieved with the partial application of germinated sorghum flour, sourdough, and lyophilized pressure-treated sorghum batter. Good results with the partial replacement of sorghum flour by starch, mainly native cassava starch, was observed. Concerning additives, emulsifiers were the most successful, but levels optimization were still required. The limited number of sorghum accessions used in the studies in comparison with the high diversity of sorghum and the scarce information on the accessions indicates that the potential of sorghum was not fully investigated for technological application. The use of accessions with quantified tannins and other phenolic compounds and resistant starch should be studied for health benefits, and the technological impacts related to the presence of these compounds must be investigated and overcome. Optimization of additive levels and association of positive results from different studies may contribute to quality improvement. Sensory evaluation and consumer studies are still incipient and very important, especially in countries in which sorghum is not used for human consumption.

Keywords: sorghum; accessions; gluten-free breads; texture; rheology; biochemical; flour quality

To cite this article: Lívia de L. de O. Pineli, et al. The use of sorghum to produce gluten-free breads: A systematic review. J Adv Nutr Hum Metab 2015; 2: e944. doi: 10.14800/janhm.944. 


\section{Introduction}

It has currently become increasingly common the restriction to gluten (protein present in the three-dimensional network wheat (Triticum spp. L.), rye (Secale cereale L.), barley (Hordeum vulgaris L.) and oats (Avena sativa L.) in diet. This is due to various adverse reactions to gluten: celiac disease, gluten or wheat allergy and gluten sensitivity ${ }^{[1,2]}$. In addition, diets with gluten restrictions have been prescribed as an adjunct in fat reduction ${ }^{[3]}$. Although there is still little scientific evidence for the latter, there have been some adherence to this type of diet, which has led to the increase of demand for gluten-free (GF) food.

The task of removing gluten from diet is difficult, since wheat and other cereals that contain gluten are consumed worldwide and are part of all the meals of the day ${ }^{[1,4]}$. Gluten is widely used by the food industry due to its technological quality such as elasticity, mass cohesion, and moisture, besides, desirable sensory characteristics like firmness, texture and uniformity.

The major challenge is the replacement of gluten network functionality in gluten-free breads (GFB). GF flours when worked in water result in viscoelastic batters instead of doughs making the production of bread a technological problem. The repulsive forces between starch granules is responsible for the lack of stability in the system and of coherent structures to entrap the air incorporated by kneading in the batter and the carbon dioxide produced by yeast fermentation. As a result, GFB are rigid and their texture are irregular and crumbly, due to irregular and unstable cells produced by a weak capacity of gas retention ${ }^{[5]}$.

Many wheat flours substitutes have been applied to produce GFB, being the most common rice flour, corn flour, potato starch, millet [Pennisetum glaucum (L.) R.Br.], quinoa (Chenopodium quinoa Wild), amaranth (Amaranthus spp. L.), buckwheat (Fagopyrum esculentum Moench.), soya [Glycine max (L.) Merr.], chickpea (Cicer arietinum L.), cassava (Manihot esculenta Crantz.) and, in a lower scale, sorghum flour ${ }^{[6]}$.

Sorghum [Sorghum bicolor (L.) Moench] is a grass, native from Africa ${ }^{[7]}$, from the same family (Poaceae) of the four most important cereals: maize (Zea mays L.), wheat, rice (Oryza sativa L.), and barley. Fifth most produced cereal in the world (61 million tons) ${ }^{[8]}$, sorghum ranks second among the cereals grown in semi-arid regions ${ }^{[9]}$. In a generally way, $40 \%$ of this production is a staple food ${ }^{[10]}$, and the rest is used for industry, alcohol, and feed. Feed sorghum is usually cheaper (10 to $15 \%$ ) than maize, thus replacing it very efficiently ${ }^{[11]}$. In addition, its flour may be used alone or together with others traditional flours in many foods, looking for reducing the food price.

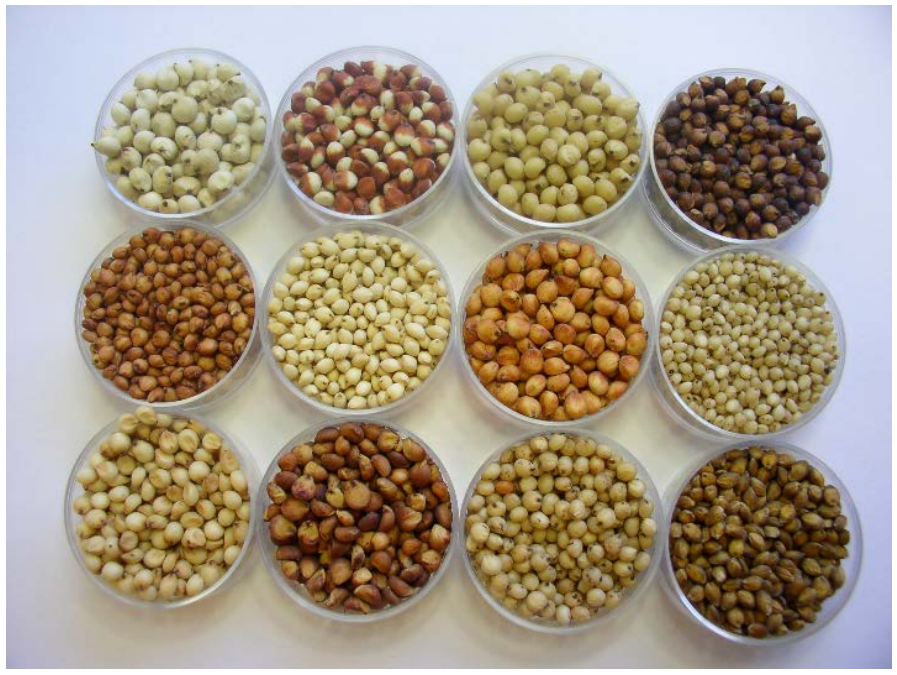

Figure 1. Example of the diversity of sorghum grains.

Furthermore, sorghum has a better performance in adverse conditions. With a C4 photosynthesis, sorghum has a better heat and drought tolerance than other crops. It has also a tolerance on acid soils where aluminum is solubilized and toxic ${ }^{[12]}$. It is a gluten-free grain ${ }^{[13]}$, with neutral flavor ${ }^{[14]}$, and alternative presence of polyphenolic compounds ${ }^{[15]}$, and of resistant starch ${ }^{[16-18]}$. Exploitation of genetic diversity, grain variability and food processing should be a key for sorghum to retain a higher fraction on food sector, ceasing to be a coarse grain and having a higher contribution on food security in a future challenging environment ${ }^{[19]}$.

The high diversity and variability of sorghum grains is expressed in the various colors from white to brown (Figure 1), partially associated with variable contents of polyphenolic antioxidants, among which are the tannins and anthocyanins ${ }^{[15]}$. Higher levels of anthocyanin are found in black sorghum. The presence of condensed tannins has an important role on human health as an antioxidant and against the obesity by reducing macromolecules digestion ${ }^{[10]}$.

Cultivated sorghum [Sorghum bicolor subsp. bicolor (L.) Moench] comprises five races (bicolor, caudatum, durra, guinea, and kafir - Figure 2) ${ }^{[20,21]}$ and ten intermediate races (combinations of five basic races). The distinction among races is mainly based on the type of spikelet and grain morphology ${ }^{[7]}$. Considering the importance of GF products and the possibility of expanding their market, and the limited use of sorghum in human diet in Western countries, especially Brazil, which is the ninth largest producer (2,1 million tons) ${ }^{[8]}$, and the greater challenge involved in the production of GFB, the objective of this review was to assess application of sorghum in the preparation of GFB and to evaluate the advantages already achieved in the application of this grain and what challenges remain. 


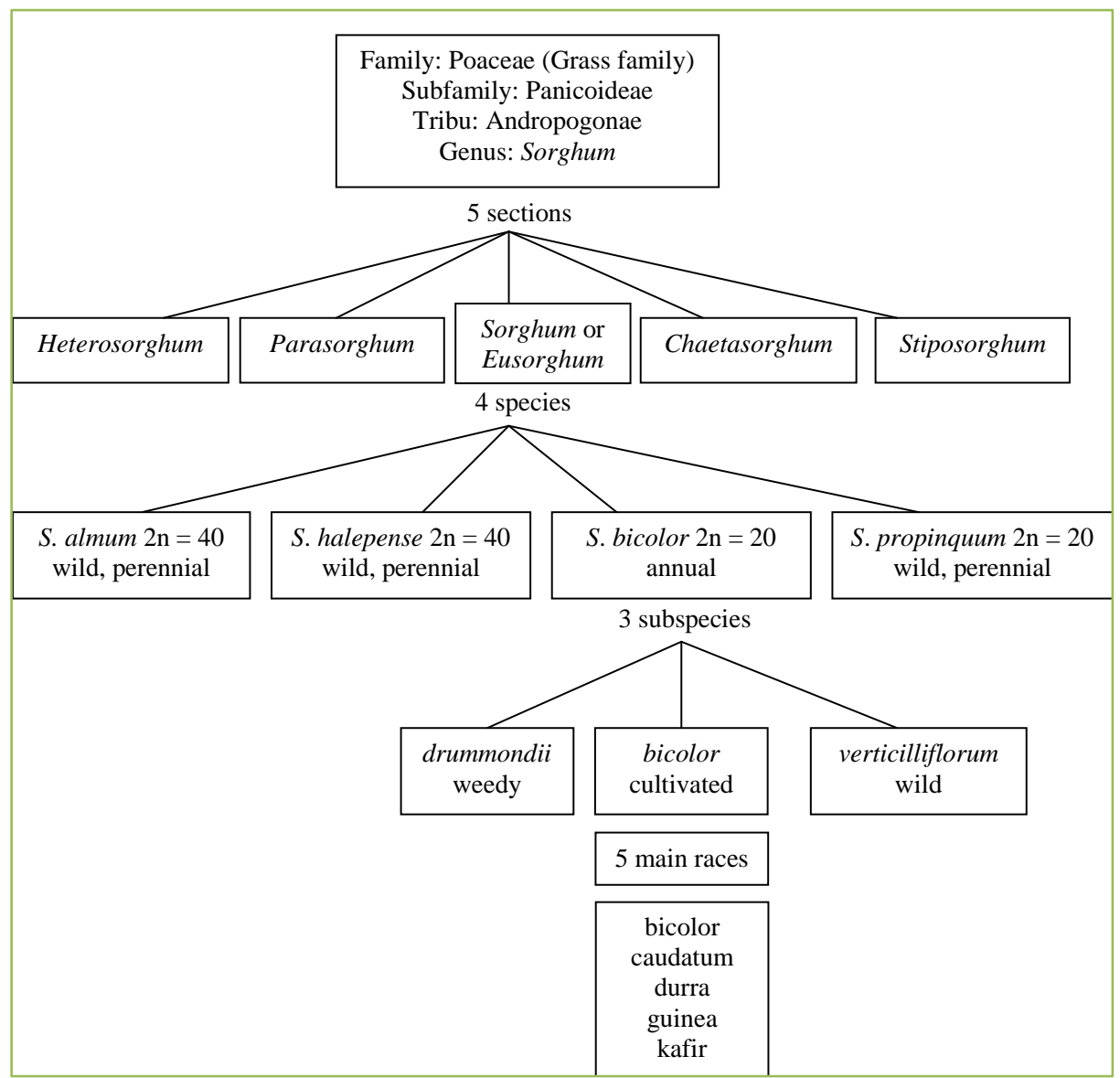

Figure 2. Taxonomy of Sorghum genus.

\section{Material and methods}

This is a cross-sectional, descriptive, exploratory study based on indirect documentation. Scientific articles published from January 2005 to June 2015 in journals indexed at the databases Scielo (Scientific Electronic Library), Lilacs (Latin America and Caribbean Science Information Center), and Scopus - which includes 100\% of Medline's (National Library of Medicine) databank using the following keywords were reviewed: sorghum, gluten-free and bread. The search was done separately in English, and all keywords were used in all possible combinations.

The inclusion criteria were: (i) original articles, (ii) articles in English, Portuguese or Spanish; (iii) studies that describe the use of sorghum in GFB. The exclusion criteria were: (i) review articles; (ii) studies in other languages; (iii) incomplete articles, (iv) monographs, dissertations, theses; (v) publications published outside the above-mentioned period.

Fourteen articles were found. After these studies were read, three articles referring to the development of composite breads with sorghum and wheat were excluded. Of the total, only eleven articles covered specifically the themes related to sorghum as a wheat flour substitute in GFB. Later, the studies were evaluated according to the country of origin, the manuscript year of publication, the objectives and types of sorghum used to produce flour and bread, types of bread, additives, sensory quality and nutritional and health promoting composition of breads made with sorghum.

\section{Results}

From the eleven studies found in our search (Table 1), one is from Thailand, one from Australia; whereas researchers from Canada, USA, Ireland, Kenya and Germany were involved in 1, 2, 4, 5 and 6 studies, respectively. In this period, studies were more concentrated in $2010(n=3), 2011(n=3)$ and $2012(n=2)$.

Despite the high diversity of sorghum worldwide ( 40,000 accessions - $\quad$ http://www.icrisat.org/crop-sorghumgenebank.htm and http://www.ars-grin.gov/npgs/stats/), most of which available, sorghum use is limited due to a lack of finely characterization, as also for many other crops ${ }^{[22]}$. Studies that use sorghum to produce GFB are mostly limited, less than 15 accessions, and accession names and grain descriptors are mostly omitted (Table 1). The use of different 
http://www.smartscitech.com/index.php/janhm

Table 1. Types of sorghum grains/flour to make bread and their composition

\begin{tabular}{|c|c|c|c|c|c|c|c|}
\hline $\begin{array}{l}\text { Description of } \\
\text { sorghum }\end{array}$ & Origin & Protein (\%) & $\begin{array}{l}\text { Ash } \\
\text { (\%) }\end{array}$ & $\begin{array}{c}\text { Lipid } \\
\text { (\%) }\end{array}$ & Fibers (\%) & Carbohydrates (\%) & Reference \\
\hline $\begin{array}{l}\text { Nine white or red } \\
\text { grain sorghum } \\
\text { hybrids }\end{array}$ & USA & $\begin{array}{c}7.8-12.9 \\
\mathrm{db}\end{array}$ & - & - & - & $\begin{array}{l}77.3-82.1^{*} \\
0.75-1.59^{* *}\end{array}$ & Schober et al. (2005) \\
\hline $\begin{array}{l}\text { Commercially } \\
\text { available sorghum } \\
\text { flour from a tan } \\
\text { plant, tannin-free, } \\
\text { white-grained } \\
\text { hybrid }\end{array}$ & USA & $8.5 \mathrm{db}$ & - & - & - & - & Schober et al. (2007) \\
\hline $\begin{array}{l}\text { Milomehl } \\
\text { red sorghum }\end{array}$ & Germany & 8.4d.b. & 0.9d.b. & 2.2d.b. & 1d.b. & 75d.b.* & Onyango et al. (2011b) \\
\hline $\begin{array}{l}\text { Sorghum grains of } \\
\text { the red variety }\end{array}$ & Thailand & 8.38 & 1.34 & 3.2 & - & - & $\begin{array}{c}\text { Phattanakulkaewmorie } \\
\text { et al., (2011) }\end{array}$ \\
\hline Sorghum flour & USA & 11.3f.b. & - & 3.3f.b. & - & - & Galle et al. (2012) \\
\hline Sorghum flour & USA & - & - & - & - & - & Wolter et al. (2013) \\
\hline
\end{tabular}

accessions is imprecise since authors frequently report the use of commercial sorghum flour ${ }^{[23-26]}$, from different suppliers of USA and Germany ${ }^{[5,27-30]}$.

Schober et al. ${ }^{[31]}$ evaluated the use of nine sorghum hybrids (7 whites and 2 reds). Sorghum grains of a not identified red variety from Thailand were used by Phattanakulkaewmorie et al. ${ }^{[32]}$. Sorghum flour was identified as white-grained by Vallons et al. ${ }^{[26]}$, and Schober et al. ${ }^{[31,33]}$, whilst red sorghum flour was used by Phattanakulkaewmorie et al. ${ }^{[32]}$ and Onyango et al. ${ }^{[5,27-30]}$. The absence of tannins in flour was described in the study of Schober et al. ${ }^{[33]}$. The composition of the flours was not fully determined in the studies, which is a drawback if we consider the variability in grains composition regarding starch, resistant starch, protein and polyphenolic compounds ${ }^{[15-17,34-36]}$.Variations on these characteristics may influence sensory and technological characteristics for a fixed formulation. Protein is the most described nutrient, ranging from 7.8 d.b to 12.9 d.b in the studies. Values reported as fresh basis were $11.3 \%{ }^{[23]}$; and $8.38 \%{ }^{[32]}$. Lipids in sorghum flour of the studies ranged from 2.52d.b. to 3.61 d.b., a narrower range than that reported by Hill et al. ${ }^{[35]}$ and Lee et al. ${ }^{[37]}$, from 1.4 to 4.9 d.b for grains. As fresh basis, Galle et al. ${ }^{[23]}$ reported $3.3 \%$ of lipids. Ashes were determined as $1.34 \%$ f.b. (red flour) by Phattanakulkaewmorie et al. ${ }^{[32]}$. Onyango et al. ${ }^{[28]}$ found $0.9 \%$ d.b. of ashes in the commercial red sorghum flour. They reported the contents of dietary fibers in sorghum flour as $1 \%$ d.b.

The role of carbohydrates in doughs and batters are well known. Onyango et al. ${ }^{[28]}$ (2011b)determined total starch and found a content of $75 \%$ d.b. Schober et al. ${ }^{[31]}$ found starch contents from $77.3 \%$ to $82.1 \%$ d.b. of total starch in nine genotypes of sorghum, besides pentosans ranging from $0.75 \%$ to $1.59 \%$ d.b. According to differential scanning calorimetry, sorghum flour present low enthalpy of gelatinization, indicative of high amounts of damage starch ${ }^{[29]}$.
Other studies on the composition of sorghum grains and flour were carried out for other contexts. Moraes et al. ${ }^{[38]}$ characterized sorghum a genotype with brown pericarp and pigmented testa, with tannins and anthocyanins as whole sorghum flour (WSF) and decorticated sorghum flour (DSF). Starch in WSF was $44.85 \%$ whereas DSF presented $68.46 \%$.

Yousif et al. ${ }^{[39]}$ evaluated the use of white or red whole grain sorghum flour on partial replacement of refined wheat flour in flat bread formulations. Dough rheology and bread quality related to chemical composition, total phenolics content and antioxidant capacity, starch digestibility (in vitro) and sensory acceptance were assessed. They found that sorghum flours presented less protein and total fibers, more ashes and similar level of lipids and carbohydrates when compared with whole wheat flour. They reported carbohydrates ranging from 81 to $84 \%$ f.b. Proteins ranged from $9.47 \%$ to $11.61 \%$ and ashes were $1.22 \%$ f.b. for white flour and $1.33 \%$ f.b. for red flour. Goodall et al. ${ }^{[40]}$ studied the feasibility to produce composite sorghum-wheat breads with normal sorghum, P721N, and high digestibility, high lysine sorghum (cv. PHD-02-4789) but they did not present composition of the flours.

According to Goodall et al. ${ }^{[40]}$, sorghum prolamins, named kafirins, compared with wheat proteins, presents a higher proportion of helical structures and a greater number of hydrophobic amino acids. The high molecular weight glutenin proteins considered as the viscoelastic component in doughs made with wheat flour, are not present in sorghum. Kafirins are also considered similar to maize zeins, but less digestible. Polypeptide chains of sorghum proteins (i.e. kafirins) are excessively short and strongly reticulated. This structure makes difficult the interaction protein-protein and impairs cohesiveness and gas holding capacity of sorghum doughs ${ }^{[41]}$. Therefore, the analysis of sorghum flour composition, concerning mainly the contents of starch and of other polysaccharides are important to evaluate the technological 
Table 2. Effects of the technological approaches on batter and bread quality of sorghum GFB

\begin{tabular}{|c|c|c|}
\hline Product & Effects on batter and bread & Reference \\
\hline Germinated flour & decreased hardness and increased cohesiveness of flat sorghum breads & $\begin{array}{l}\text { Phattanakulkaewmorie } \\
\text { et al., (2011) }\end{array}$ \\
\hline \multirow[t]{2}{*}{ Pressure treated flour } & Increase of batter consistency. & Vallons et al. (2010) \\
\hline & $\begin{array}{l}\text { Delayed staling for breads (replacement of } 2 \% \text { SF); low specific volume and poor bread } \\
\text { quality (replacement of } 10 \% \text { of SF). }\end{array}$ & \\
\hline \multirow[t]{2}{*}{ Sourdough } & $\begin{array}{l}\text { Protein degradation, stronger starch gel, improved bread quality, prevention of a hole in } \\
\text { bread crumb }\end{array}$ & Schobert et al. (2007) \\
\hline & Synthesis of oligosaccharides, resulting in nutritional benefits & Galle et al. (2012) \\
\hline Potato starch & $\begin{array}{l}\text { Lower gelatinization temperature in comparison to maize starch, resulting in an earlier } \\
\text { increase of the batter/crumb consistency during baking. }\end{array}$ & Schober et al., 2007 \\
\hline \multirow[t]{2}{*}{$\begin{array}{l}\text { Native } \\
\text { (NCS) }\end{array}$} & $\begin{array}{l}\text { Decreased elastic and increased viscous character of the batters with increasing starch } \\
\text { concentration. }\end{array}$ & $\begin{array}{l}\text { Onyango et al., 2010a, } \\
\text { 2011b }\end{array}$ \\
\hline & $\begin{array}{l}\text { Reduced firmness when used in association (up to 50\%) with sorghum starch. Good } \\
\text { distribution of pores on the crumb surface and the pore sizes tended to decrease with } \\
\text { increasing starch content. Breads became lighter in color with increasing starch content } \\
\text { Increased crumb cohesiveness and elasticity. Better crumb characteristics in comparison } \\
\text { with PGCS. }\end{array}$ & \\
\hline $\begin{array}{l}\text { Pregelatinized } \\
\text { starch (PGCS) }\end{array}$ & $\begin{array}{l}\text { Several exposed active groups that form multiple bonds with water so that the strength } \\
\text { of the batter increases with increasing starch concentration. } \\
\text { In comparison with NCS: decrease of temperature of gelatinization, more viscous } \\
\text { batters, viscoelastic strength of the batters increased with increasing starch } \\
\text { concentration. Cracked crust surfaces. Crumb dampness increased with increasing } \\
\text { starch content. Increased undesirable adhesiveness. }\end{array}$ & $2011 b$ \\
\hline Rice flour & Improved crumb cohesiveness and resilience & Onyango et al., 2011a \\
\hline Corn starch & $\begin{array}{l}\text { Decline crumb properties (increased firmness and chewiness; decreased cohesiveness, } \\
\text { resilience and springiness ) on storage }\end{array}$ & Onyango et al., 2011a \\
\hline Milk protein & $\begin{array}{l}\text { Reduced bread height by collapsing the top, increased baking loss, and reduced crumb } \\
\text { cohesiveness interfere with the starch gel by competition for water or by disrupting its } \\
\text { uniformity. }\end{array}$ & Schober et al., 2005 \\
\hline Xanthan gum & $\begin{array}{l}\text { Decrease of temperature of gelatinization. Negative effects on crumb structure. Partial } \\
\text { reversion of negative effects of milk proteins }\end{array}$ & Schober et al., 2005 \\
\hline HPMC & Increased viscosity of batters. Improved crumb texture in association with sourdough. & Schober et al., 2007 \\
\hline Cellulose derivatives & $\begin{array}{l}\text { Lower resistances to deformation, except for CMC at } 2.4 \% \text {. No decrease in crumb } \\
\text { firmness and staling rate of GFB }\end{array}$ & Onyango et al., 2009 \\
\hline Emulsifiers & $\begin{array}{l}\text { Higher elastic recovery of doughs. Decreased crumb firmness. Slowed staling rate. At } \\
\text { higher concentrations, weakened crumbs. }\end{array}$ & Onyango et al., 2009 \\
\hline Egg white powder & Eliminated several textural defects associated with GFB & Onyango et al., 2009 \\
\hline$\alpha$-amylase & $\begin{array}{l}\text { No influence on consistency of the batters. Decreased crumb firmness, cohesiveness, } \\
\text { springiness, resilience and chewiness but increased undesirable adhesiveness. }\end{array}$ & Onyango et al., 2010a \\
\hline $\begin{array}{l}\text { Microbial } \\
\text { transglutaminase }\end{array}$ & $\begin{array}{l}\text { Decreased the batters' resistance to deformation. Increased crumb firmness and } \\
\text { chewiness, whereas increasing incubation time decreased crumb cohesiveness, } \\
\text { chewiness and resilience. }\end{array}$ & Onyango et al., 2010b \\
\hline
\end{tabular}

potential of the flour.

\section{Types of bread and technological strategies to improve sorghum GFB quality}

Regarding the types of breads, except for the study of Phattanakulkaewmorie et al. ${ }^{[32]}$, all evaluated the use of sorghum flour to produce leavened breads. Technological approaches to improve bread quality involved germination of sorghum grains, high pressure, application of sourdough and the use of starches and additives (Table 2).

Changes in sorghum flour and batter were carried out by means of germination to activate mainly the amylases ${ }^{[32]}$. The use of sorghum flours with germinated grains decreased hardness and increased cohesiveness of flat sorghum breads.

High pressure treatment ${ }^{[26]}$ was applied on sorghum flours to alter the structure of proteins and starch to improve baking properties of GF cereals. The increase of batter consistency at pressures higher than $600 \mathrm{MPa}$ was associated with gelatinization of starch induced by pressure. In addition, the use of freeze-dried sorghum batters at $600 \mathrm{MPa}$ replacing 2 and $10 \%$ of untreated sorghum flour delayed bread staling at the lower level of replacement, whereas breads with $10 \%$ of replacement presented a low specific volume and a poor quality.

Schober et al. ${ }^{[33]}$ and Galle et al. ${ }^{[23]}$ evaluated the use of sourdough to improve the quality of sorghum bread. According to Hamada et al. ${ }^{[42]}$, the activity of lactic acid bacterial proteases to hydrolyze soluble proteins in the protein matrix attached to starch granules is the main role of sourdough. Schober et al. ${ }^{[33]}$ concluded that sourdough prevented flattop and a tendency to form a hole in the crumb. Protein degradation in small peptides decreased the interference of proteins on starch gelatinization. The higher resistance to deformation of starch gel has contributed to 
desirable texture of sorghum GFB.

The results of Galle et al. ${ }^{[23]}$ indicated that exopolysaccharides formed during sourdough fermentation softened the crumbs of fresh and stored sorghum breads. The best shelf life improvements were observed with the production of dextran. Moreover, oligosaccharides produced during sorghum sourdough fermentation contributed to the nutritional benefits of sorghum GFB.

Most of the studies evaluated the effect of gums, stabilizers, milk powder and pre gelatinized starch on gas entrapment and stabilizing mechanisms of the GF batters.

Schober et al. ${ }^{[31]}$ evaluated the influences of additional ingredients (xanthan gum and skim milk) in sorghum GFB. The use of these products had negative effects on crumb structure, but improved crust browning. They reduced crumb cohesiveness, bread height by collapsing the top and increased baking loss. Milk proteins and lactose probably interfered with the starch gel by competition for water or by disrupting its uniformity. However, negative effects of skim milk powder were masked by high levels of xanthan gum, which retained water in the sorghum GFB. On the other hand, Ahlborn et al. ${ }^{[43]}$ observed that the addition of milk proteins to GF rice breads resulted in a matrix similar to gluten, and it increased loaf volume, improved crumb texture and delayed bread staling.

Schober et al. [33] have shown that $2 \%$ of hydroxypropyl-methylcellulose (HPMC) associated to sourdough was effective to improve bread quality. They demonstrated that potato starch showed better bread quality instead of cornstarch. The lower gelatinization temperature of potato starch in comparison with cornstarch results in an earlier increase of the batter/crumb consistency during baking and prevents GFB from collapsing.

Onyango et al. ${ }^{[27]}$ studied the use of the cellulose derivatives microcrystalline cellulose (MCC), carboxymethylcellulose (CMC), methylcellulose (MC), hydroxypropylmethylcellulose (HPMC), hydroxypropylcellulose (HPC) and emulsifiers such as glycerol monostearate (GMS), sodium stearoyl-2-lactylate (SSL), calcium stearoyl-2-lactylate (CSL), and diacetyl tartaric acid esters of mono and diglycerides (DATEM) on dough rheology and bread texture of sorghum GFB. Emulsifiers strengthened the doughs, softened the crumbs and delayed staling of sorghum GFB but cellulose-derivatives did not show the same positive effect. According to the authors, the optimization of emulsifier concentration between 0.4 and $2.4 \%$ could provide further improvement to crumb characteristics of GFB made with pre gelatinized cassava starch and sorghum. Moreover, the effect of the addition of egg white powder $(6.7 \%)$ on the removal of many textural drawbacks associated with GFB was reported.

Onyango et al. ${ }^{[5]}$ studied the use of $\alpha$-amylase and the comparison between native and pre gelatinized cassava starch to produce sorghum GFB. The increase of $\alpha$-amylase concentration showed minimal effect on the consistency of the batters. On the other hand, decreased firmness, cohesiveness, springiness, resilience and chewiness and increased adhesiveness was observed when $\alpha$-amylase concentration was increased for each formulation. The increase of crumb adhesiveness by the use of $\alpha$-amylase resulted in a decreased overall quality, making the application of the enzyme discouraged for sorghum GFB. The partial replacement of sorghum with native cassava starch resulted in low firmness, chewiness and adhesiveness and high springiness. Differently, the partial substitution of sorghum with pre gelatinized cassava starch led to high cohesiveness and resilience of GFB.

The use of microbial transglutaminase (MTG) on rheological and baking characteristics of sorghum GFB was evaluated by Onyango et al. ${ }^{[30]}$. This study showed significant changes in the rheological properties of the batter when MTG was added, inducing a strengthening effect of protein network associated with cross-linking action. Increasing enzyme concentration led to higher crumb firmness and chewiness, due to increased resistance to deformation and lower strain, but it had no influence on springiness, cohesiveness or resilience. A sandy mouthfeel probably associated with a high amount of damaged starch from sorghum flour was detected by sensory evaluation.

In another study, Onyango et al. ${ }^{[29]}$ evaluated GF sorghum bread made from cassava, corn, potato or rice starch and sorghum in different proportions and demonstrated that the botanical origin and the amount of starch affect batter rheology and crumb quality of sorghum GFB. Generally, the increase of starch proportion improves crumb properties of sorghum bread. Cassava-sorghum and rice-sorghum GF breads had better crumb properties than corn-sorghum or potato-sorghum breads. Sorghum bread containing 50\% cassava starch had the best overall crumb properties. These results may represent an improvement to those of Schober et al. ${ }^{[31,33]}$, in which corn and potato starches were applied.

The comparison between native and pre gelatinized cassava starches was revisited by Onyango et al. ${ }^{[28]}$, who tested new proportions of starch: sorghum flour. Native starch concentration was positively associated with the fluidness of the batters. On the other side, the firmness of the batters increased on the proportion of pre gelatinized starch content. 
http://www.smartscitech.com/index.php/janhm

The batters prepared with native starch and sorghum flour provided bread with better crumb properties than batters containing pre-gelatinized starch. The increased concentration of native or pre gelatinized starch decreased crumb firmness and chewiness. However, pre gelatinized starch was associated with the increase of bread adhesiveness impairing bread quality. Better crumb properties of sorghum GFB by increasing the addition of native cassava starch were related to increasing cohesiveness, elasticity and resiliency, and decreasing adhesiveness, chewiness and firmness. The best ratios of native cassava starch and sorghum flour were 30:70 or 40:60.

\section{Nutritional composition and health promoting properties of sorghum GFB}

A carryover effect of nutritional characteristics of sorghum grains and flour to the breads should be expected and better explored. Among the studies, only three of them analyzed some nutritional impact of sorghum application in GFB and each study analyzed different nutritional components that affects health.

According to Phattanakulkaewmorie et al. ${ }^{[32]}$, sorghum is a rich source of various phytochemicals, including tannins, phenolic acids, anthocyanins, phytosterols and policosanols. In this study, total phenolic contents in sorghum flour (SF) were significantly higher than that of wheat flour (WF) (1.87 compared to $0.83 \mathrm{mg}$ GAE/g). Comparing WF with SF, the latter presents more fat and ash $(3.20 \mathrm{~g} / 100 \mathrm{~g} ; 1.34 \mathrm{~g} / 100 \mathrm{~g}$, respectively) than WF $(0.86 \mathrm{~g} / 100 \mathrm{~g} ; 0.45 \mathrm{~g} / 100 \mathrm{~g})$ and less protein $(8.38 \mathrm{~g} / 100 \mathrm{~g})$. However, the amount of proteins is more similar to wheat flour as the other cereals and the potential to replace wheat flour was hypothesized.

Galle et al. ${ }^{[23]}$ showed that the use of sourdough fermentation in sorghum GFB has produced exopolysaccharides and oligosaccharides that contributed to nutritional and health benefits such as reduced glycemic index, increased satiety, and improved bowel function.

Wolter et al. ${ }^{[25]}$ have compared nutritional aspects related to carbohydrates and glycaemic index (GI) from sorghum gluten-free-bread and wheat bread. They showed that sorghum GFB presented more total available carbohydrates (1634mg/4g) in comparison to wheat bread (1543mg/4g), but lower GI (72 and 100 respectively). This can be explained by the mechanisms governing the glycaemic response and the rate of starch digestion plays a central role and is controlled by a combination of factors: size of the starch granules, extent of gelatinization, their composition and structure, protein and lipid content of the matrix, besides interactions with tannins.
None of the studies fully assessed the nutritional composition of GFB sorghum and their impact on health. More studies should be conducted to fully elucidate the nutritional impact of the use of sorghum in GFB.

Barros et al. ${ }^{[44]}$ demonstrated that the interactions between tannins and other phenolics with starch decrease its in vitro digestibility of sorghum grains. This should be an interesting property of sorghum grains with tannins for application in GFB with lower glycemic index. Polymeric proanthocyanidins from sorghum was shown to naturally modify starch by interacting strongly with amylose and are thus most suitable to produce foods with higher resistant starch $^{[16]}$.

In a study conducted by Moraes et al. ${ }^{[38]}$ with sorghum flour (brown pericarp and pigmented forehead), a negative correlation was observed for Estimated Glycemic Index (EGI) and the content of phenolic compounds, specific flavonoids, antioxidant activity and fiber (soluble, insoluble, and total beta-glucans). However, authors did not find correlation between EGI and resistant starch.

\section{Discussion}

In spite of the strategical position of sorghum for food security, studies on sorghum GFB are still limited, reflecting its low use in human feeding. An important limitation found from the studies is the little information on the accessions of sorghum used in the studies. The use of limited types of commercial sorghum impairs the analysis of the real potential of sorghum to technological, sensory and nutritional properties of sorghum for application in breads. Studies on the carry-over effect of sorghum grains health-promoting properties to sorghum GFB are very important to assess the nutritional advantages of the consumption of sorghum breads in comparison with other cereals. Indeed, tannins are not present on three major cereals (corn, wheat and rice), thus its presence should be an example of incomplete domestication of sorghum ${ }^{[45]}$ that could be wisely used to health benefits. In this context, the analyses of glycemic index and of antioxidant capacity of sorghum GFB made with grains rich in resistant starch and / or phenolic compounds should be carried out in further studies.

From the technological standpoint, it is possible to identify as remaining challenges the proposals from the study of Onyango et al. ${ }^{[27]}$, in which the optimization of amounts of emulsifiers is required to improve the rheological and textural properties of the sorghum batters and GFB, as from the study of Vallons et al. ${ }^{[26]}$ in which the association between high pressure and hydrocolloids are hypothesized as beneficial for bread quality. Optimization is still necessary for other 
http://www.smartscitech.com/index.php/janhm

additives successfully adopted in other GFB starting from a combination of the formulations, which probably include the use of native cassava starch, egg white powder, emulsifiers and the use of hydrocolloids.

Finally, detailed sensory studies are necessary once sorghum flour is not used for human feeding in several countries, like Brazil, where consumption is limited to animal feeding. Consumer studies are necessary to determine intention to purchase with respect of the information of the sorghum as ingredient by populations that are not used to it. Descriptive studies could also help assess the technological potential of different genotypes and drive choices of what type of sorghum flour would result in better sensory characteristics. Association between instrumental and sensory analysis would improve the evaluation of real impacts of technological strategies on perceived quality. Acceptance and descriptive tests have been already performed for composite breads of sorghum: wheat ${ }^{[39,46]}$.

It is important to notice that most of sorghum breeding programs are applied to improve agronomic characteristics aiming a high yield. Few works were conducted to study the grain quality of sorghum seeking human uses from a high number of accessions ${ }^{[35,36,47]}$. Future studies should aim at evaluating the resulting grains from breeding programs from the perspective of quality and potential for food technology applications.

\section{Conclusion}

Despite the high diversity and variability of sorghum, studies on sorghum GFB are focused on white or red commercial sorghum flours of very few sorghum accessions, not mentioning other grain descriptors, accession names and identifiers. Studies with hybrids presented limited characterization of the flours. The use of sorghum associated to its tannins and other polyphenolic contents as well as higher contents of resistant starch is still narrow in spite of its strategic importance to produce healthier breads. Successful results of the evaluated studies could be combined to further attempts to prepare higher quality sorghum GFB. Besides, nutritional and sensory responses associated with consumer studies directed to populations not accustomed to sorghum consumption are crucial for assessing the technological potential of sorghum and expansion of its consumption, effectively contributing to food security.

\section{Authors' contributions}

Lívia de L. de O. Pineli: systematization of articles, writing and revising contribution throughout the manuscript. Renata P. Zandonadi: design of systematic review, writing contribution on introduction and nutritional aspects of sorghum. Raquel B. A. Botelho: writing contribution on introduction and nutritional aspects of sorghum. Viviani R. de Oliveira: writing on technological aspects of sorghum gluten-free breads. Lúcio F. de Alencar Figueiredo: writing on botanical aspects of sorghum, sorghum production, revising throughout the manuscript, figures.

\section{References}

1. Sapone A, Bai J, Ciacci C, Dolinsek J, Green P, Hadjivassiliou M, et al. Spectrum of gluten-related disorders: consensus on new nomenclature and classification. BMC Medicine 2012; 10: 13.

2. Fasano A, Araya M, Bhatnagar S, Cameron D, Catassi C, Dirks $\mathrm{M}$, et al. Federation of International Societies of Pediatric Gastroenterology, Hepatology, and nutrition consensus report on celiac disease. J Pediatr Gastroenterol Nutr 2008; 47: 214-219.

3. Soares F, de Oliveira Matoso R, Teixeira L, Menezes Z, Pereira S, Alves A, et al. Gluten-free diet reduces adiposity, inflammation and insulin resistance associated with the induction of PPAR-alpha and PPAR-gamma expression. J Nutr Biochem 2013; 24: 1105-1111.

4. Araújo H, Araújo W, Botelho R, Zandonadi R. Celiac disease, eating habits and practices and life quality of life. Rev Nutr Campinas 2010; 23: 467-474.

5. Onyango C, Mutungi C, Unbehend G, Lindhauer M. Batter rheology and bread texture of sorghum-based gluten-free formulations modified with native or pregelatinised cassava starch and $\alpha$-amylase. Int J Food Sci Tech 2010; 45: 1228-1235.

6. Aguilar N, Albanell E, Miñarro B, Gallardo J, Capellas M. Influence of final baking technologies in partially baked frozen gluten-free bread quality. J Food Sci 2015; 80: E619-E626.

7. Harlan JR, de Wet JMJ. A simplified classification of cultivated sorghum. Crop Sci 1972; 12: 172-176.

8. FAOSTAT. Production, Crops. Available at http://faostat.fao.org. 2015.

9. Ramu P, Billot C, Rami JF, Senthilvel S, Upadhyaya HD, Ananda Reddy L, et al. Assessment of genetic diversity in the sorghum reference set using EST-SSR markers. Theor Appl Genet 2013; 126: 2051-2064.

10. Awika J, Rooney L. Sorghum phytochemicals and their potential impact on human health. Phytochemistry 2004; 65: 1199-1221.

11. Hancock J. Value of sorghum and sorghum coproducts in diets for livestock. In Sorghum: origin, history, technology, and production. Edited by. Smith CW, Frederiksen RA. New York: John Wiley \& Sons, Ins; 2000: 731-749.

12. Magalhaes J, Liu J, Guimarães C, Lana U, Alves V, Wang Y-H, et al. A gene in the multidrug and toxic compound extrusion (MATE) family confers aluminum tolerance in sorghum. Nat Genet 2007; 39: 1156-1161.

13. Pontieri P, Mamone G, De Caro S, Tuinstra M, Roemer E, Okot J, et al. Sorghum, a healthy and gluten-free food for celiac patients as demonstrated by genome, biochemical, and immunochemical analyses. J Agric Food Chem 2013.

14. Ciacci C, Maiuri L, Caporaso N, Bucci C, Del Giudice L, Rita Massardo D, et al. Celiac disease: In vitro and in vivo safety and palatability of wheat-free sorghum food products. Clin Nutr 2007; 26: 799-805. 
http://www.smartscitech.com/index.php/janhm

15. Dykes L, Rooney L. Sorghum and millet phenols and antioxidants. J Cereal Sci 2006; 44: 236-251.

16. Barros F, Awika J, Rooney L. Effect of molecular weight profile of sorghum proanthocyanidins on resistant starch formation. J Sci Food Agric 2014; 94: 1212-1217.

17. Sang Y, Bean S, Seib P, Pedersen J, Shi Y-C. Structure and functional properties of sorghum starches differing in amylose content. J Agric Food Chem 2008; 56: 6680-6685.

18. Khan I, Yousif A, Johnson S, Gamlath S. Effect of sorghum flour addition on resistant starch content, phenolic profile and antioxidant capacity of durum wheat pasta. Food Res Int 2013; 54: 578-586.

19. Godfray HC, Beddington J, Crute I, Haddad L, Lawrence D, Muir J, et al. Food security: the challenge of feeding 9 billion people. Science 2010; 327: 812-818.

20. de Wet JMJ. Systematics and evolution of Sorghum Sect. Sorghum (Gramineae). Am J Bot 1978; 65: 477-484.

21. Kimber C. Origins of domesticated sorghum and its early diffusion in India and China. In Sorghum: Origin, history, technology, and production. Edited by. Smith W, Frederiksen RA. New York, USA: John Wiley and Sons; 2000: 3-98.

22. Glaszmann JC, Kilian B, Upadhyaya HD, Varshney RK. Accessing genetic diversity for crop improvement. Curr Opin Plant Biol 2010; 13: 167-173.

23. Galle S, Schwab C, Dal Bello F, Coffey A, Gänzle M, Arendt E. Influence of in-situ synthesized exopolysaccharides on the quality of gluten-free sorghum sourdough bread. Int J Food Microbiol 2012; 155: 105-112.

24. Schober T, Bean S, Boyle D. Gluten-free sorghum bread improved by sourdough fermentation: biochemical, rheological, and microstructural background. J Agric Food Chem 2007; 55: 5137-5146.

25. Wolter A, Hager A-S, Zannini E, Arendt E. In vitro starch digestibility and predicted glycaemic indexes of buckwheat, oat, quinoa, sorghum, teff and commercial gluten-free bread. J Cereal Sci 2013; 58: 431-436.

26. Vallons K, Ryan L, Koehler P, Arendt E. High pressure-treated sorghum flour as a functional ingredient in the production of sorghum bread. Eur Food Res Technol 2010; 231: 711-717.

27. Onyango C, Unbehend G, Lindhauer M. Effect of cellulose-derivatives and emulsifiers on creep-recovery and crumb properties of gluten-free bread prepared from sorghum and gelatinised cassava starch. Food Res Int 2009; 42: 949-955.

28. Onyango C, Mutungi C, Unbehend G, Lindhauer M. Rheological and textural properties of sorghum-based formulations modified with variable amounts of native or pregelatinised cassava starch. Food Sci Technol - LWT 2011; 44: 687-693.

29. Onyango C, Mutungi C, Unbehend G, Lindhauer M. Modification of gluten-free sorghum batter and bread using maize, potato, cassava or rice starch. Food Sci Technol - LWT 2011; 44: 681-686.

30. Onyango C, Mutungi C, Unbehend G, Lindhauer M. Rheological and baking characteristics of batter and bread prepared from pregelatinised cassava starch and sorghum and modified using microbial transglutaminase. J Food Eng 2010; 97: 465-470.

31. Schober T, Messerschmidt M, Bean S, Park S-H, Arendt E. Gluten-free bread from sorghum: quality differences among hybrids. Cereal Chem 2005; 82: 394-404.

32. Phattanakulkaewmorie N, Paseephol T, Moongngarm A. Chemical compositions and physico-chemical properties of malted sorghum flour and characteristics of gluten free bread. World Academy of Science, Engineering and Technology 2011; 5: 384-390.

33. Schober T, Bean S, Boyle D. Gluten-free sorghum bread improved by sourdough fermentation: biochemical, rheological, and microstructural background. J Agric Food Chem 2007; 55: 5137-5146.

34. de Alencar Figueiredo LF, Davrieux F, Fliedel G, Rami JF, Chantereau J, Deu M, et al. Development of NIRS equations for food grain quality traits through exploitation of a core collection of cultivated sorghum. J Agric Food Chem 2006; 54: 8501-8509.

35. Hill H, Slade Lee L, Henry R. Variation in sorghum starch synthesis genes associated with differences in starch phenotype. Food Chem 2012; 131: 175-183.

36. Sukumaran S, Xiang W, Bean S, Pedersen J, Kresovich S, Tuinstra $\mathrm{M}$, et al. Association mapping for grain quality in a diverse sorghum collection. Plant Genome J 2012; 5: 126-135.

37. Lee BH, Weller CL, Cuppett SL, Carr TP, Walter J, Martínez I, et al. Grain sorghum lipids: extraction, characterization, and health potential. Advances in Cereal Science: Implications to Food Processing and Health Promotion 2011; 1089: 149-170.

38. Moraes É, Marineli R, Lenquiste S, Steel C, Menezes C, Queiroz $\mathrm{V}$, et al. Sorghum flour fractions: correlations among polysaccharides, phenolic compounds, antioxidant activity and glycemic index. Food Chem 2015; 180: 116-123.

39. Yousif A, Nhepera D, Johnson S. Influence of sorghum flour addition on flat bread in vitro starch digestibility, antioxidant capacity and consumer acceptability. Food Chem 2012; 134: 880-887.

40. Goodall M, Campanella O, Ejeta G, Hamaker B. Grain of high digestible, high lysine (HDHL) sorghum contains kafirins which enhance the protein network of composite dough and bread. J Cereal Sci 2012; 56: 352-357.

41. Taylor JRN, Belton PS. Pseudocereals and less common cereals. Grain properties and utilization potential. In Sorghum. Edited by. Berlin: Springer; 2002: 25-91.

42. Hamada S, Suzuki K, Aoki N, Suzuki Y. Improvements in the qualities of gluten-free bread after using a protease obtained from Aspergillus oryzae. J Cereal Sci 2013; 57: 91-97.

43. Ahlborn G, Pike O, Hendrix S, Hess W, Huber C. Sensory, mechanical, and microscopic evaluation of staling in low-protein and gluten-free breads. Cereal Chem 2005; 82: 328-335.

44. Barros F, Awika J, Rooney L. Interaction of tannins and other sorghum phenolic compounds with starch and effects on in vitro starch digestibility. J Agric Food Chem 2012; 60: 11609-11617.

45. Wu Y, Li X, Xiang W, Zhu C, Lin Z, Wu Y, et al. Presence of tannins in sorghum grains is conditioned by different natural alleles of Tannin1. Proc Natl Acad Sci USA 2012; 109: 10281-10286.

46. Carson L, Setser C, Sun X. Sensory characteristics of sorghum composite bread *. Int J Food Sci Tech 2000; 35: 465-471.

47. de Alencar Figueiredo LF, Sine B, Chantereau J, Mestres C, Fliedel G, Rami JF, et al. Variability of grain quality in sorghum: association with polymorphism in Sh2, Bt2, SssI, Ae1, Wx and O2. Theor Appl Genet 2010; 121: 1171-1185. 